\title{
Wykorzystanie światłowodów w inżynierii medycznej
}

\section{Application of fiber optics in medical engineering}

\section{Streszczenie}

W artykule przedstawiono możliwości wykorzystania światłowodów w inżynierii medycznej. Zostały przedstawione laboratoryjne wyniki badań inteligentnego systemu monitorującego podłoże pacjenta w opiece pielęgnacyjnej. Oprócz informacji o ułożeniu pacjentów na materacu uzyskujemy w systemie monitorowania także informacje o aktualnej temperaturze pacjenta i wilgotności podłoża.

Słowa kluczowe: diagnostyka; światłowody; pomiary odkształceń; inżynieria medyczna

\section{Abstract}

The article issues the possibilities of using optical fiber in medical engineering. They were presented laboratory results of intelligent monitoring system of patients' underlay in nursing process. The monitoring system provides information about the patients position on a mattress and also the current patients temperature and underlay humidity.

Keywords: diagnostics; optical fiber, measurements deformation; medical engineering

\section{Wstęp}

Urządzenia i systemy diagnostyczne bazujące na światłowodach wykorzystywane są szeroko w telekomunikacji, w przemyśle, transporcie i wielu aplikacjach specjalistycznych.

Światłowody mają też inne istotne zastosowania - stosowane są one jako czujniki służące do pomiarów wartości różnych wielkości fizycznych, w szczególności temperatury i ciśnienia, oraz naprężeń, odkształceń, położenia, odległości, wibracji, a ostatnio także wilgotności $[1 \div 3]$.

W ramach nowych kierunków kształcenia studentów na studiach technicznych pojawiła się inżynieria medyczna, łącząca w sobie wiedzę i doświadczenie niezbędne do tworzenia nowych technologii inżynierskich oraz ich zastosowania w praktyce medycznej.

Leczenie chorych u których samodzielność i swoboda poruszania się na łóżku jest znacznie ograniczona (urazy wielonarządowe, porażenia, opatrunki gipsowe) lub całkowicie wyłączona (pacjent nieprzytomny) wymaga od personelu medycznego, zwłaszcza pielęgniarskiego intensywnego nadzoru. Nadzór ten obejmuje ocenę parametrów życiowych (tętno, ciśnienie tętnicze, saturacja krwi, temperatura itp.) a także szeroko rozumianą profilaktykę zapobiegającą powikłania związanym z przedłużającym się unieruchomieniem pacjenta. Do takich powikłań zaliczamy odleżyny, skostnienia stawowe, przykurcze mięśni, ucisk nerwów obwodowych, zapalenie żył, zapalenie płuc itp... Odleżyny najczęściej tworzą się w okolicy miednicy, kości krzyżowej, na łokciach i piętach. Dlatego co dwie godziny należy zmieniać ułożenie ciała chorego. W szpitalach często brakuje pielęgniarek do obsługi pielęgnacyjno-medycznej pacjentów, stąd pomysł na kompleksowy system monitorowania podłoża (materacy) pacjentów w którym inteligentny układ elektroniczny pozwala na przesyłanie informacji o aktualnym ułożeniu pacjenta i czasie jego przebywania w tym położeniu.
Odpowiedzią na powyższą problematykę był przedmiot zgłoszenia patentowego Inteligentny system monitorujący podłoże pacjenta w opiece pielęgnacyjnej. Oprócz informacji o ułożeniu pacjentów uzyskujemy w systemie monitorowania także informacje o aktualnej temperaturze pacjenta i wilgotności podłoża spowodowanego np. wyrwanym wenflonem, problemem fizjologicznym, wymiocinami itp.

\section{Opis systemu pomiarowego}

W systemie monitorowania wykorzystywane są czujniki FBG posiadające niewielkie rozmiary i bardzo małą masę co pozwala na duże zmniejszenie wagi systemu pomiarowego w porównaniu do czujników elektrycznych. Obecnie najbardziej rozpowszechnione, są czujniki FBG, które mierzą odkształcenia i mogą być traktowane jako zamiennik powszechnie stosowanych tensometrów elektrooporowych. Systemy pomiarowe wykorzystujące czujniki światłowodowe znajdują zastosowanie wszędzie tam, gdzie dotychczas nie było możliwe zastosowanie większej ilości sensorów z uwagi na ich zbyt dużą masę wraz z okablowaniem. Są one łatwiejsze $\mathrm{w}$ instalacji w porównaniu do czujników elektrycznych. Na pojedynczym światłowodzie może być naświetlonych kilka siatek Bragga kontrolowanych przez jeden kanał urządzenia. Zastosowanie interrogatorów wielokanałowych pozwala na utworzenie gęstej siatki punktów pomiarowych. W porównaniu do innych systemów wykorzystujących pojedyncze urządzenia do odczytywania wyników z pojedynczych czujników, rozwiązanie to znacznie obniża koszty pomiarów. Ponadto, rożnego rodzaju wartości mogą być odczytywane przez jeden kanał (ugięcia, temperatura,

Prof. dr hab. inż. Jerzy Kwaśniewski; dr hab. inż. Janusz Juraszek prof. AGH - Akademia Górniczo-Hutnicza w Krakowie.

Autor korespondencyjny/Corresponding author. kwasniew@agh.edu.pl 
ciśnienie). Ponieważ nie istnieje praktycznie ograniczenie w długości światłowodu, czujniki mogą być oddalone kilka kilometrów od urządzenia sterującego bez potrzeby zastosowania wzmacniaczy.

Zasada działania czujnika FBG bazuje na liniowej zmianie długości fali Bragga (rys.1). Siatka dyfrakcyjna, utworzona jest za pomocą promieniowania UV, rejestruje zmiany współczynnika załamania światła wzdłuż rdzenia. Zmiany długości fali świetlnej są wprost proporcjonalne do zmian odkształcenia i temperatury elementu, na którym jest umieszczony światłowód z siatką Bragg'a. Umieszczenie światłowodu polega na przyklejeniu lub zamocowaniu mechanicznych. Znajomość odkształcenia umożliwia poprzez związki fizyczne wyznaczenia naprężenia w kierunku osi siatki Bragg'a [2,5]. Długość odbitej fali określona jest równaniem:

$$
\lambda_{B}=2 n_{e f} \cdot \Lambda
$$

gdzie:

$n_{e f}-$ efektywny współczynnik załamania rdzenia włókna,

$\Lambda$ - okres siatki

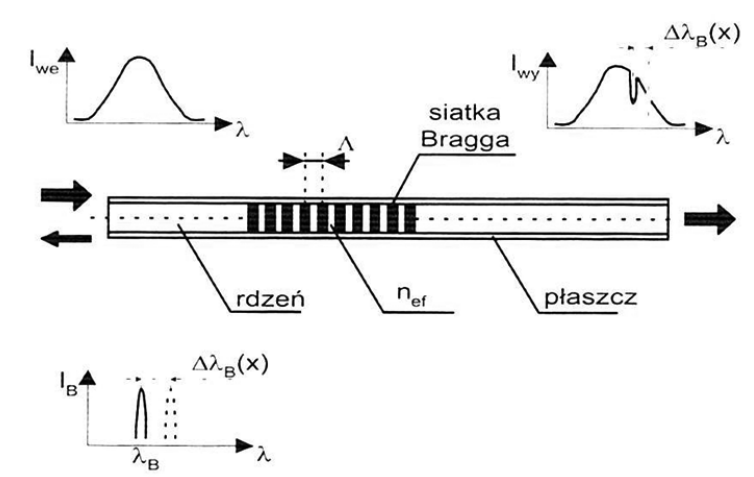

Rys. 1. Istota pomiaru odkształceń za pomocą światłowodu z siatką Bragg'a FBG

Fig. 1. Strain measurement using optical fiber mesh Bragg FBG

Do zalet czujników światłowodowych FBG można zaliczyć:

- odporność w chemicznie agresywnym środowisku,

- odporność na wysokie napięcie elektryczne i zakłócenia elektromagnetyczne,

- możliwość badania odkształceń do 10\%,

- niewielkie wymiary - możliwość stosowania w małych elementach konstrukcji,

- długa żywotność sięgająca ponad 20 lat,

- możliwość podłączenia wielu czujników na jednej linii światłowodowej.

Czujniki FBG nie wymagają osobnego zasilania. Dzięki temu są całkowicie odporne na interferencje wywołane przez zakłócenia elektrostatyczne lub źródła częstotliwości radiowych. Ponadto, sensory mogą być stosowane w ciężkich, eksplozyjnych warunkach. Charakteryzują się również wysoką wytrzymałością zmęczeniową. Czujniki FBG wykazują niezmienność swoich własności pomiarowych w czasie. Dzięki temu, że należą do grupy czujników pasywnych, posiadają zerowy dryft a co za tym idzie, mogą być używane przez wiele lat bez konieczności powtórnej kalibracji $[8,10]$. Dzięki tej własności szczególne zastosowanie znalazły przy długotrwałym monitoringu.

Jedną z zalet omawianych czujników jest możliwość naświetlenia znacznej liczby siatek Bragg'a w jednym włóknie światłowodowym, w odległości zarówno kilku milimetrów, jak i w odstępie kilku kilometrów. Ponadto odpowiednie rozmieszczenie tych elementów umożliwia realizację czujników reagujących nie tylko na zmianę temperatury i odkształcenia, ale też takich parametrów jak wilgotność.
Głównym elementem systemu do pomiarów odkształceń i/lub temperatury jest interrogator - optoelektryczne urządzenie odczytujące zmianę długości fali wprost proporcjonalną do odkształcenia siatki Bragga na pojedynczym światłowodzie. Interrogator jest znanym urządzeniem szeroko opisywanym w literaturze. Pełny układ pomiarowy tworzy interrogator, czujniki FBG (czujniki z siatką Bragga) oraz komputer wraz z inteligentnym oprogramowaniem $[6,7,9]$. Oprogramowanie pozwala na rozróżnienie obciążenia czujników spowodowanych różnym ułożeniem pacjenta, na ilościowy pomiar temperatury której wartość wcześniej jest kalibrowana do panujących warunków, na pomiar jakościowy wilgotności we wskazanych miejscach materaca. Na ekranie komputera pokazywana jest informacja o mierzonych parametrach jednocześnie na wszystkich łóżkach z wpiętą siecią światłowodową w jeden obwód.

Na rysunku 2 przedstawiono przykładowe rozwiązanie zawierające podstawowe elementy inteligentnego systemu monitorującego składającego się materaców 1 z częścią zasadniczą 2 oraz warstwą wierzchnią 3 w której umieszczono sieć czujników światłowodowych FBG 7 lub sieć światłowodów 4 połączoną z jednym interrogatorem 5 i części elektronicznej zawierającej komputer 6 z oprogramowaniem, połączony sprzęgaczem z siecią. Sieć światłowodowa umieszczona w kolejnych materacach 1 jest łączona szeregowo.
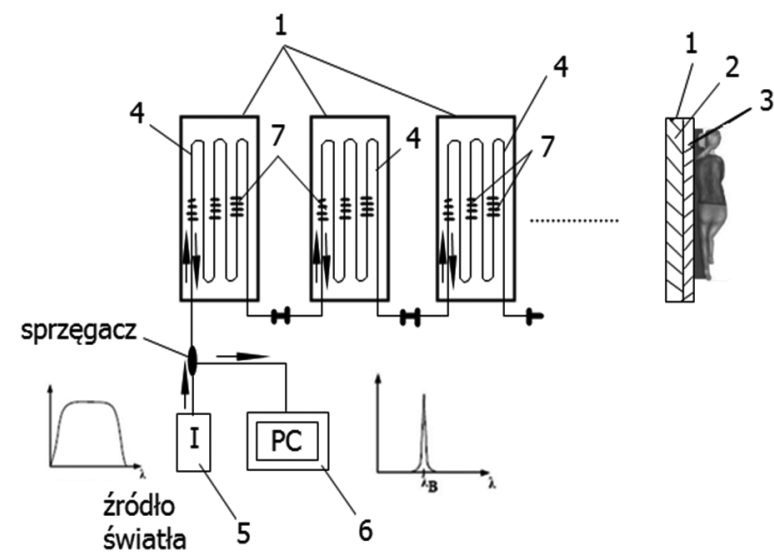

Rys. 2. Schemat połączenia sieci światłowodowej

Fig. 2. Diagram of fiber optic network

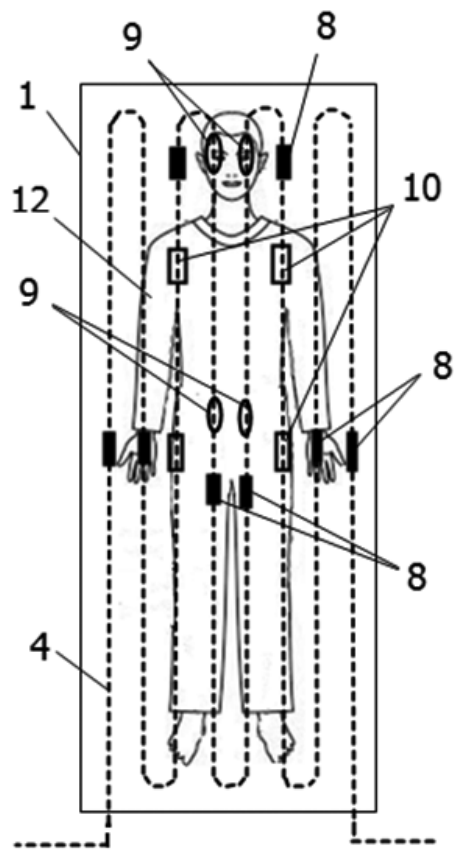

Rys. 3. Rozmieszczenie czujników FBG na powierzchni materaca Fig. 3. FBG sensor arrangement on the surface of the mattress 
Na rysunku 3 przedstawiono przykładowe rozmieszczenie czujników FBG na powierzchni materaca. Zmiana pozycji pacjenta 12 - pozycja na plecach lub na boku - określana jest przez pomiar naprężeń powstających w wyniku rozciągania lub ściskania światłowodu powodującego deformację siatki Bragga, co prowadzi do zmiany jej gęstości, a w efekcie do zmiany długości fali światła odbijanego przez czujnik FBG 10, co jest rejestrowane w komputerze 6. Czujniki te usytuowane są na wysokości barków i miednicy (bioder). Zmiany temperatury pacjenta powodują zmianę współczynnika odbicia materiału, z którego wykonany jest rdzeń czujnika FBG 9 i następuje też rozszerzenie struktury, co dodatkowo wpływa na rozkład oczek siatki Bragga czujników FBG 9 i umożliwia rejestrację ciepłoty ciała pacjenta 12. Czujniki temperatury 9 usytuowane są pod głową i w okolicy kręgosłupa lędźwiowego. Są one kalibrowane w zależności od ewentualnych dodatkowo pojawiających się osłon np. cerat, poduszek itp. Czujniki FBG wilgotności 8 usytuowane są na światłowodzie $4 \mathrm{w}$ miejscach materaca 1 gdzie prawdopodobieństwo wystąpienia zawilgocenia jest największe i są to okolice dłoni gdzie ewentualne wyrwanie wenflonu może spowodować wilgoć, okolice narządów płciowych (problemy fizjologiczne pacjentów), okolice głowy dla przypadków pojawienia się wymiocin.

\section{Badania laboratoryjne}

Układ pomiarowy rejestruje temperaturę pacjentów oraz naprężenia wynikające z jego ułożenia na materacu. System jest dowolnie konfigurowalny, co oznacza, że jednocześnie możemy wprowadzić wiele progów alarmowych w zależności od zaistniałej sytuacji. Alarm może być generowany w momencie:

- przekroczenia wyznaczonego progu temperatury,

- stałego wzrostu temperatury w krótkim wyznaczonym czasie,

- przemieszczenia się pacjenta. Inne zalety to:

- rejestracja temperatury mierzonej w określonym materacu,

- bardzo dokładna lokalizacja miejsca zmiany temperatury,

- długookresowy monitoring temperatury,

- możliwość wielokrotnego odtwarzania pomiarów temperatury,

- kabel sensoryczny jest łatwy w montażu (jak kabel elektryczny),

- brak oddziaływania kabla na pacjenta,

- brak przepływu prądu w kablu (bezwybuchowość, kompatybilność EMC),

- możliwość pracy w trudnych warunkach (zapylenie, kurz), odporność na korodowanie, promienie UV, wodę.
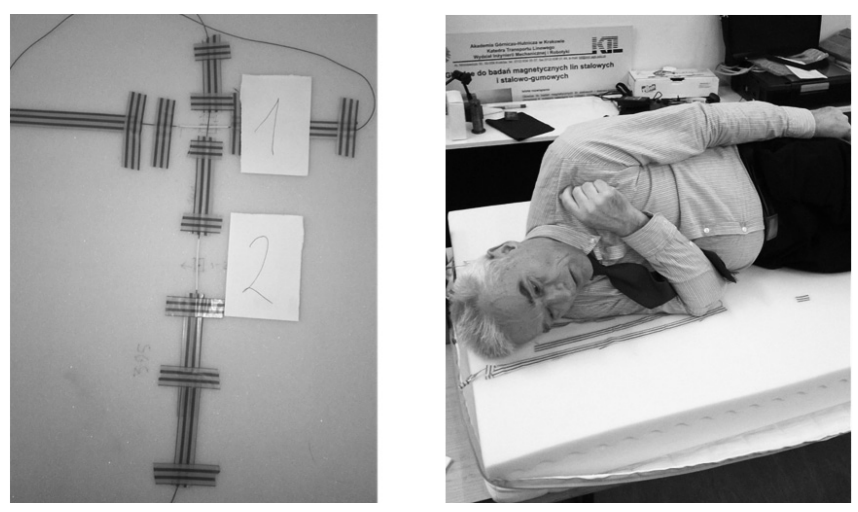

Rys. 4. Badania laboratoryjne systemu pomiarowego Fig. 4. Laboratory tests of the measuring system
W warunkach laboratoryjnych (rys.4) wykonano pierwsze badania układu pomiarowego. Próba polegała na obserwacji sygnału światłowodowego w różnych położeniach pacjenta: leżenie na plecach, na prawym i lewym boku. Na rysunku 5 przedstawiono zmiany sygnału wywołane różnym obciążeniem światłowodu w zależności od ułożenia pacjenta. Czujnik nr 1-1(kolor czerwony) ułożono w osi materaca. Czujnik 1-2 (niebieski) znajduje się po prawej stronie materaca. Czujnik 1-3 (zielony) znajduje się w okolicach lędźwi. Czujnik 1-4 (czarny) znajduje się po lewej stronie materaca. Najbardziej jest obciążony czujnik nr 1-1 i wynika to ze zmiany położenia i zwiększonego nacisku okolic kręgosłupa. Ale dzięki obserwacji czujnika nr 1-4, którego wartości są większe niż czujnika nr 1-2, wiemy że pacjent leży na lewym boku a kiedy na prawym boku. Wszystkie wahania, które można zaobserwować na wykresie wynikają z tego że materiał z którego wykonany jest materac nie jest idealnie sprężysty. Na wykresie przedstawiono wartości odkształcenia przy różnych położeniach pacjenta.

Czujniki FBG 8 (rys.3) służące do pomiaru wilgotności pokryte są cienką powłoką polimerową o odpowiedniej grubości, która pod wpływem wilgoci pęcznieje dając informację o stanie zawilgocenia materaca 1. Na wyświetlaczu komputera (rys.6) podawana jest jednocześnie informacja o stanie wilgotności materaców grupy pacjentów, ich aktualnej temperaturze ciała oraz o aktualnej ich pozycji (na plecach lub na boku) i czasie ułożenia w tej pozycji. Czujniki FBG wilgotności 8 usytuowane są na światłowodzie 4 w miejscach materaca $1 \mathrm{gdzie}$ prawdopodobieństwo wystąpienia zawilgocenia jest największe (okolice dłoni, bioder, głowy). Czujniki temperatury 9 usytuowane są pod głową i pod biodrami pacjenta 12, zaś czujniki odkształceń 10 usytuowane są w miejscach o największym obciążeniu materaca (pod ramionami i biodrami).

$\mathrm{Na}$ rysunku 5 przedstawiono zarejestrowane odkształcenia światłowodu w mikrostrainach dla różnych położeń pacjenta na materacu ( na osi poziomej czas próbkowania).

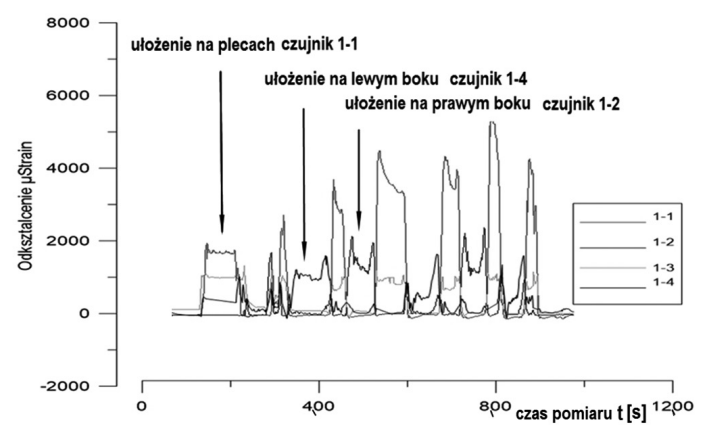

Rys. 5. Zarejestrowane odkształcenia światłowodu w różnych położeniach pacjenta

Fig. 5. Registered deformation of the fiber at different positions of the patient

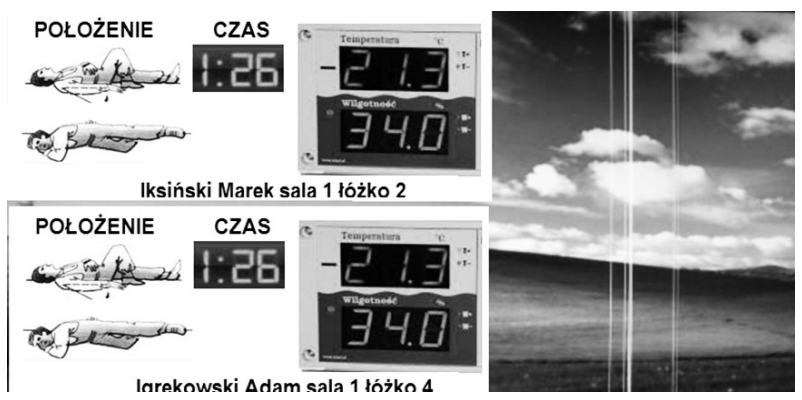

Rys. 6. Przykładowy obraz modułu z informacją o położeniu pacjenta, czasie pobytu $w$ danym położeniu, temperaturze i wilgotności Fig. 6. Sample image of the module with information about the position of the patient, stay time in the position, temperature and humidity 


\section{Wnioski}

Przedstawiony Inteligentny system monitorujący podłoże pacjenta w opiece pielęgnacyjnej umożliwia monitorowanie zmian położenia pacjenta, jego aktualnej temperatury oraz zmiany wilgotności w wybranych miejscach materaca. Światłowodowe czujniki FBG posiadają szereg zalet w stosunku do innych tradycyjnych systemów, takich jak mały rozmiar i ciężar, chemiczna obojętność, biozgodność, zdolności do multipleksowania. Mogą one znaleźć w przyszłości zastosowanie w aplikacjach związanych z zagadnieniami biomechanicznymi oraz inżynierii rehabilitacyjnej.

\section{Literatura}

[1] Juraszek J.: Ciągłe pomiary odkształceń konstrukcji inżynierskich. Monografia. CEIT, a.s., 2013.

[2] Alexandre Ferreira da Silva, Anselmo Filipe Gonçalves, Paulo Mateus Mendes, José Higino Correia: FBG Sensing Glove for Monitoring Hand Posture, IEEE SENSORS JOURNAL, Vol. 11, No. 10, October 2011

[3] Afonso, J. A., Macedo, P., Silva, H. D., Correia, J. H., Rocha, L. A. (2010) Design and Implementation of Multi-User Wireless Body Sensor Networks", Journal on Advances in Networks and Services, IARIA Publisher, 3(1\&2): 62-74.

[4] Antunes, P., Varum, H., and André, P. (2011). Uniaxial fiber Bragg grating accelerometer system with temperature and cross axis insensitivity, Measurement, 44(1): 1-5.

[5] Augousti, A. T., Maletras, F. X., and Mason,J. (2005). Improved fibre optic respiratory monitoring using a figure-of-eight coil, Physiological Measurement, 26(5): 585-590.

[6] Bao, H., Dong, X., Zhao, C., Shao, L. Y., Chan, C. C., and Shum, P. (2010). Temperature insensitive FBG tilt sensor with a large measurement range, Optics Communications, 283(6): 968-970.

7] Bilro, L., Oliveira, J. G., Pinto,J. L., Nogueira, R. N. (2011). A reliable low-cost wireless and wearable gait monitoring system based on a plastic optical fibre sensor, Measurement Science and Technology, 22(4): 1-7. Institute of Physics Paper 045801. Boerkamp, M., Lamb.

[8] D. W., Lye, P. G. (2007, July). Using an intrinsic, exposed core, optical fibre sensor to quantify chemical scale formation, Journal of Physics: Conference Series, 76(1): 1-7. Institute of Physics Paper 012016.

[9] Carmo, J. P., Silva, A. F., Rocha, R. P., and Correia, J. H. (2012). Application of fiber Bragg gratings to wearable garments, IEEE Sensors Journal, 12(1): 261-266.

[10] Cup, E. H., Pieterse, A. J., ten Broek-Pastoor, J. M., Munneke, M., van Engelen, B. G., Hendricks, H. T., van der Wilt, G. J., Oostendorp, R. A. (2007). Exercise therapy and other types of physical therapy for patientswith neuromuscular diseases: A systematic review, Archives of Physical Medicine and Rehabilitation, 88(11): 1452-1464. 